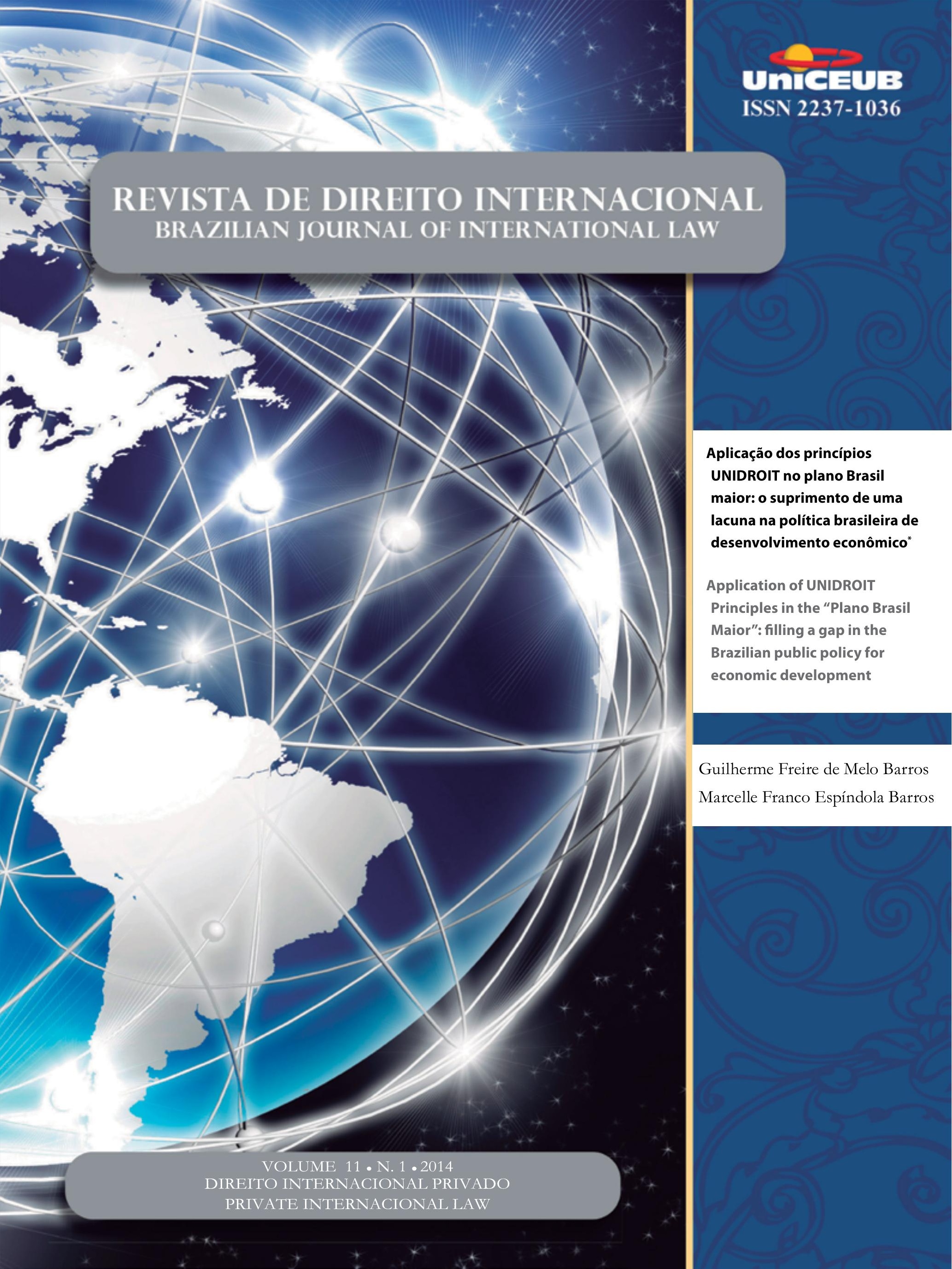




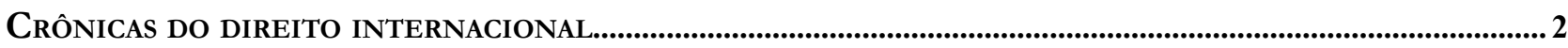

Nitish Monebhurrun

Alice Rocha da Silva

Julia Motte-Baumvol

Rafael Freitas de Oliveira

Roberta Greco

CRÔNICAS DO DIREITO INTERNACIONAL DOS INVESTIMENTOS .11

Nitish Monebhurrun

Reconhecimento E ExecuÇão de Sentenças Estrangeiras: anÁlise do projeto Em andamento na Conferência da Haia de Direito Internacional Privado

Nadia de Araujo

Fabrício Bertini Pasquot Polido

Os CASAMENTOS E AS PARCERIAS ENTRE PESSOAS DO MESMO SEXO NO DIREITO INTERNACIONAL PRIVAdO BRASILEIRO: ASPECTOS TRANSNACIONAIS DAS FAMÍLIAS CONTEMPORÂNEAS.

Bruno Rodrigues de Almeida

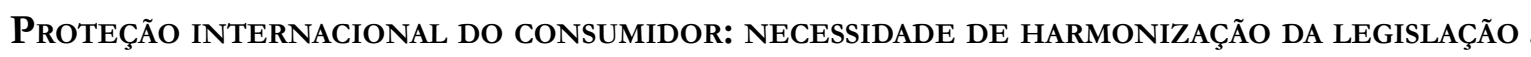
54

Héctor Valverde Santana

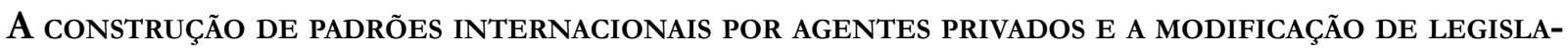
Ção NACIONAL: ALTERAÇÃo do PADRÃo DE CONTABILIDADE PARA EMPRESÁRIOS NO BRASIL.

Cleíse Nascimento Martins Costa

THE DEBATE ON COMPANIES' LIABILITY FOR INTERNATIONAL ENVIRONMENTAL DAMAGES: A COMPARISON BETWEEN THE JURISDiCTIONAL RULES OF THE EUROPEAN UNION AND THE UNITED STATES

Carina Costa de Oliveira

DesenVOlVIMENTO E APLICAÇÃo DA TEORIA dos VíNCUlOS MAIS ESTREITOS NO DIREITO INTERNACIONAL PRIVADO: POR UMA REDISCUSSÃO DO MÉTODO DE SOLUÇÃO DO CONFLITO DE LEIS 101

Jamile Bergamaschine Mata Diz

Rodrigo Vaslin Diniz

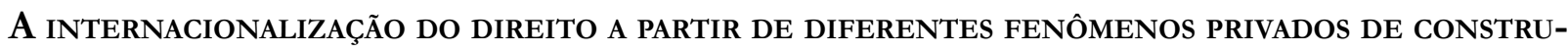
ÇÃO NORMATIVA 117

Fernando Lopes Ferraz Elias 
Leilane Serratine Grubba

Human TRAFFicking: IDENTIFYING FORCED LABOR IN MULTINATIONAL CORPORATIONS \& THE IMPLICATIONS OF LIABILITY

Tara M. Parente

Aplicação dos princípios UNIDROIT no Plano Brasil maior: o SUPRIMENTO de UMA lacuna NA POLÍTICA BRASILEIRA DE DESENVOLVIMENTO ECONÔMICO

Guilherme Freire de Melo Barros

Marcelle Franco Espíndola Barros

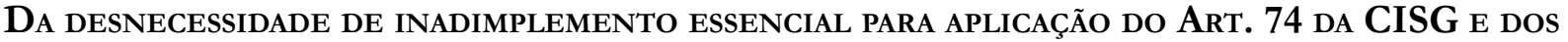
DANOS EFETIVAMENTE RECUPERÁVEIS

Renata Caroline Kroska

ESSAY ON UNEQUAL TREATIES AND MODERNITY THROUGH THE EXAMPLE OF BILATERAL INVESTMENT TREATIES

Nitish Monebhurrun

CONCEITOS DE RELAÇÕES INTERNACIONAIS E TEORIA DO DIREITO DIANTE DOS EFEITOS PLURALISTAS DA GLOBALIZAÇÃO: GOVERNANÇA GLOBAL, REGIMES JURÍDICOS, DIREITO REFLEXIVO, PLURALISMO JURÍDICO,

CORREGULAÇÃO E AUTORREGULAÇÃO . 216

Gabriela Garcia Batista Lima

\section{Outros Temas}

CONVENÇão SOBRE OS DIREITOS DAS PESSOAS COM DEFICIÊNCIA: COMO "INVISÍVEIS" CONQUISTARAM SEU ESPAÇO .230

Luana da Silva Vittorati

Matheus de Carvalho Hernandez 


\title{
Aplicação dos princípios UNIDROIT no plano Brasil maior: o suprimento de uma lacuna na política brasileira de desenvolvimento econômico*
}

\author{
Application of UNIDROIT Principles in the "Plano \\ Brasil Maior": filling a gap in the Brazilian public \\ policy for economic development
}

\author{
Guilherme Freire de Melo Barros** \\ Marcelle Franco Espíndola Barros ${ }^{* * *}$
}

*Recebido em 04.02.2014

Aprovado em 17.05.2014

** Procurador do Estado do Paraná; Mestrando em Direito Econômico e Socioambiental pela PUC-PR; LL.M em Contratos Internacionais e Resolução de Disputas pela Universidade de Turim/Itália; Pósgraduado em Direito Processual Civil pelo Instituto Romeu Bacellar. E-mail: barrosguilherme@yahoo.com.br

*** Advogada; Mestranda em Direito Econômico e Socioambiental pela PUC-PR; Bolsista da Capes; LL.M em Contratos Internacionais e Resolução de Disputas pela Universidade de Turim/ Itália; Pós-graduada em Propriedade Intelectual pela PUC-RJ. E-mail: marcelle_espindola@yahoo.com.br

\section{Resumo}

O presente artigo analisa a aplicação dos Princípios UNIDROIT de Contratos Comerciais Internacionais para promoção do desenvolvimento econômico do Brasil. O estudo parte do exame do plano de desenvolvimento econômico do atual governo, o Plano Brasil Maior. $O$ posto a exame é a verificação se os Princípios UNIDROIT de Contratos Comerciais Internacionais podem se inserir na política de desenvolvimento econômico do Plano Brasil Maior. Isso porque, ao confrontar os objetivos relativos ao comércio internacional com as correspondentes medidas adotadas, verifica-se que não há qualquer medida efetiva no que tange ao objetivo de facilitar o comércio internacional. Há, portanto, uma lacuna a ser suprida no plano governamental. Nesse contexto, demonstra-se de que forma os Princípios UNIDROIT de Contratos Comerciais Internacionais podem ser aplicados para atender a esse objetivo, de modo a facilitar as transações comerciais internacionais e, com isso, gerar desenvolvimento.

Palavras-chave: Princípios UNIDROIT de Contratos Comerciais Internacionais. Plano Brasil Maior. Comércio internacional. Desenvolvimento econômico.

\begin{abstract}
This article analyzes the application of the UNIDROIT Principles of International Commercial Contracts in the Brazilian economic development. The study scrutinizes the present public policy for economic development, named "Plano Brasil Maior", in order to demonstrate that the objectives related to foreign trade will not be achieve by the measures taken by the Government. To fill this gap, the article shows how the UNIDROIT Principles could be applied to facilitate and enhance international trade in Brazil.
\end{abstract}

Keywords: UNIDROIT Principles of International Commercial Contracts. Brazilian public policy for economic development. "Plano Brasil Maior". International trade. 


\section{Introdução}

Atualmente, quando se trata de temas ligados ao desenvolvimento, o primeiro aspecto que se destaca é o de que o crescimento econômico de uma nação está contido no conceito de desenvolvimento, mas não o exaure. Este é mais amplo do que aquele, pois açambarca também diversos outros fatores, como condições de vida — saúde, saneamento, educação etc. - e exercício de direitos políticos.

Essa compreensão de desenvolvimento é relativamente nova. Durante muitos séculos ao longo da História, a prosperidade de uma nação esteve intimamente ligada à geração de riqueza, oriunda da formação de excedentes de produção. Tais excedentes poderiam ser fruto de guerras e escravidão - como no Império Romano, até o século $\mathrm{V}$-, ou de trocas comerciais - como em Portugal e Holanda nos séculos XIV e XVI — , ou ainda fruto de produções industriais, como na Inglaterra do século XVIII. O ponto em comum era a associação entre desenvolvimento e crescimento econômico.

Somente a partir do século XX, e mais fortemente depois da II Guerra Mundial, é que se amplia a percepção de que o desenvolvimento está ligado à melhoria da qualidade de vida das pessoas. Nesse contexto, o crescimento econômico passa a ser visto como uma ferramenta, um meio para se alcançar o desenvolvimento.

Ainda que meio para alcançar fim maior e superior, fato é que o crescimento econômico domina amplo espaço de atenção de governos em quase todo mundo a exceção mais notável é provavelmente o Butão, que não mede a progressão de seu produto interno bruto (PIB).

Ao longo das últimas décadas, o Brasil tem buscado promover o desenvolvimento social por meio de programas que melhorem a vida da população brasileira e reduzam a pobreza e a desigualdade - tais como o Programa Fome Zero, o Bolsa Família e o Minha Casa, Minha Vida. Dentro de um sistema capitalista como o brasileiro, porém, a viabilização desses programas demanda necessariamente recursos econômicos vultosos. Como consequência, o Brasil nunca deixou de ter o crescimento econômico em sua ordem do dia, e o atual governo desenvolveu sua estratégia através do Plano Brasil Maior.

Em âmbito internacional, medidas de estímulo ao desenvolvimento têm sido tomadas não só pelos próprios países, mas também por organizações supranacionais, tanto no plano econômico quanto jurídico. Em relação a este último, tem-se verificado cada vez mais a regulação de negócios jurídicos internacionais por instrumentos legais supranacionais, dentre os quais figuram os Princípios de Contratos Comerciais Internacionais, elaborados pelo Instituto Internacional para Unificação do Direito Privado UNIDROIT.

Metodologicamente, o problema que orienta o presente estudo é o seguinte: é possível que os Princípios UNIDROIT de Contratos Comerciais Internacionais se insiram na política de desenvolvimento econômico do Plano Brasil Maior?

Para proceder ao presente estudo, inicialmente serão elencados os aspectos do Plano Brasil Maior que tratam do comércio exterior, com a identificação da lacuna quanto a um de seus objetivos. Em seguida, passa-se à explicação do que são os Princípios UNIDROIT de Contratos Comerciais Internacionais e de que forma soem ser aplicados no comércio internacional. Por fim, demonstra-se como sua aplicação pode ser útil na facilitação do comércio internacional e, via de consequência, no alcance das metas econômicas traçadas pelo Brasil para seu desenvolvimento.

\section{Desenvolvimento econômico nacional e Plano Brasil Maior}

O Brasil sofreu grandes transformações em seu perfil político-econômico nos últimos 30 (trinta) anos. A década de 1980 marcou a transição do governo militar para a redemocratização do país, período que culminou com dois grandes marcos, a promulgação da Constituição da República de 1988, a Constituição Cidadã, e a realização das primeiras eleições diretas para Presidente da República desde Jânio Quadros em 1960 - a célebre eleição presidencial de 1989 foi disputada por 22 candidatos, da qual saiu vencedor Fernando Collor de Mello. ${ }^{1}$

Superada a luta brasileira pela redemocratização, o maior desafio da nação era conseguir a estabilização de sua moeda. Até 1990, o mercado brasileiro era extremamente fechado, as importações eram de pequena monta, a concorrência se limitava a poucos players. O governo tentou solucionar a questão com seu

1 CONTI, Mario Sérgio. Notícias do Planalto: a imprensa e Fernando Collor. São Paulo: Companhia das Letras, 1999. p. 324. 
famigerado Plano Collor. Se por um lado fracassou ao efetuar um radical bloqueio das poupanças no afã de tentar reduzir a quantidade de dinheiro em circulação e, com isso, controlar a inflação, a empreitada teve, ao menos, o mérito de iniciar um processo de abertura dos mercados brasileiros aos produtos importados, dentro da concepção de que era necessário aumentar a concorrência para gerar maior eficiência e menores preços. $^{2}$

A consolidação econômica foi alcançada finalmente a partir de meados da década de 1990, com o Plano Real, no governo Fernando Henrique Cardoso, e posteriormente mantida pelos governos seguintes. ${ }^{3}$

Nesses últimos trinta anos, o Brasil deixou de ser um país protecionista e de mercado fechado para se tornar a $6^{\mathrm{a}}$ maior economia mundial, com um PIB aproximado de 2,253 trilhões de dólares. ${ }^{4}$ Essa evolução econômica foi fortemente influenciada pelo comércio internacional e isso se reflete nos dados históricos da balança de importações e exportações brasileiras. De acordo com a série histórica do Banco Central, em 1991, as exportações brasileiras somaram US $\$ 31,620$ bilhões, e as importações, US\$21,040 bilhões. ${ }^{5}$ Em 2012, o resultado da abertura econômica se refletiu nos superlativos números, segundo dados do Ministério do Desenvolvimento, Indústria e Comércio Exterior: foram exportados US $\$ 243$ bilhões e importados US\$ $233^{6}$ — aproximadamente US\$ 1 bilhão de dólares por dia útil. Tais valores fizeram do Brasil em 2012 o $22^{\circ}$ maior importador e o $22^{\circ}$ maior exportador mundial. ${ }^{7}$

Parte desse crescimento se deu no período 20072010, dentro do Plano de Desenvolvimento Produtivo. Naquela oportunidade, a meta era que as exportações

2 LEITÃO, Miriam. Saga brasileira: a longa luta de um povo por sua moeda. São Paulo: Record, 2011. p. 43.

3 LEITÃO, Miriam. Saga brasileira: a longa luta de um povo por sua moeda. São Paulo: Record, 2011. p. 230.

4 BANCO MUNDIAL. Disponível em: <http://data. worldbank.org/country/brazil>. Acesso em: 05 dez. 2013.

5 BRASIL. Banco Central. Série histórica do balanço de pagamentos. Disponível em: <http://www.bcb.gov.br/?SERIEBALPAG>. Acesso em: 05 dez. 2013.

6 BRASIL. Ministério do Desenvolvimento, Indústria e Comércio Exterior. Balança comercial brasileira: dados consolidados 2013, janeiro-junho. Disponível em < http://www.desenvolvimento. gov.br/arquivos/dwnl_1380110216.pdf>. Acesso em: 05 dez. 2013.

7 BRASIL. Ministério do Desenvolvimento, Indústria e Comércio Exterior. Balança comercial brasileira: dados consolidados 2012. Disponível em: <http://www.desenvolvimento.gov.br/ arquivos/dwnl_1365787109.pdf,>. Acesso em: 05 dez. 2013. brasileiras alcançassem a marca de 1,25\% do comércio internacional. $^{8}$ A meta foi atingida e superada. A participação do Brasil no comércio internacional alcançou, em 2010, 1,3\% - um significativo avanço, embora ainda atrás dos demais países que compõem o grupo dos BRICS. ${ }^{9}$

Para dar continuidade a seu crescimento econômico, o Governo Federal lançou o Plano Brasil Maior em agosto de 2011, que concentra a política industrial, tecnológica e de comércio exterior do País, e está dividido em quatro tópicos: dimensão setorial, dimensão sistêmica, medidas e metas. ${ }^{10}$

No presente artigo, o foco está nos aspectos do Plano que tocam ao comércio exterior.

Na dimensão setorial, o tema está tratado na diretriz estruturante $\mathrm{n}^{\circ} 4$, que apregoa o seguinte: $:^{11}$

Diretriz Estruturante $4-$ Diversificação das Exportações (mercados e produtos) e Internacionalização Corporativa, com foco nos seguintes objetivos:

Promoção de produtos manufaturados de tecnologias intermediárias e de fronteira intensivos em conhecimento.

Aprofundamento do esforço de internacionalização de empresas via diferenciação de produtos e agregação de valor.

Enraizamento de empresas estrangeiras e estímulo à instalação de centros de Pesquisa e Desenvolvimento (P\&D) no país.

Na dimensão sistêmica, o Plano prevê os seguintes objetivos: ${ }^{12}$

8 BRASIL. Ministério do Desenvolvimento, Indústria e Comércio Exterior. Política de Desenvolvimento Produtivo. Disponível em: <http://www.pdp.gov.br/paginas/macrometas. aspx?Language $=\mathrm{E} \&$ Country $=\mathrm{BR}>$. Acesso em: $12 \mathrm{dez} .2013$.

9 CESAR, Susan Elizabeth Martins; SATO, Eiiti. A Rodada Doha, as mudanças no regime do comércio internacional e a política comercial brasileira. Revista Brasileira de Politica Internacional, v. 55, n. 1, p. 185, 2012.

10 BRASIL. Ministério do Desenvolvimento, Indústria e Comércio Exterior. Plano Brasil Maior. Disponível em: <http:// www.brasilmaior.mdic.gov.br/conteudo/128>. Acesso em: 05 dez. 2013.

11 BRASIL. Ministério do Desenvolvimento, Indústria e Comércio Exterior. Plano Brasil Maior. Disponível em: <http://www. brasilmaior.mdic.gov.br/conteudo/128>. Acesso em: 05 dez 2013.

12 BRASIL. Ministério do Desenvolvimento, Indústria e Comércio Exterior. Plano Brasil Maior. Disponível em: <http:// www.brasilmaior.mdic.gov.br/conteudo/128>. Acesso em: 05 dez. 2013. 


\subsection{Comércio Exterior}

Inclui objetivos de curto, médio e longo prazo:

Melhoria nos instrumentos financeiros e tributários de estímulo às exportações;

Defesa comercial, consolidação e harmonização de regras tarifárias;

\subsection{Facilitação do comércio}

Estímulo à internacionalização de empresas nacionais visando a ampliação de mercados e o acesso a novas tecnologias; e

Atração de centros de pesquisa e desenvolvimento de empresas estrangeiras para o país.

As medidas adotadas que mais especificamente se referem ao comércio exterior foram as seguintes: ${ }^{13}$

\section{Tabela 1}

\begin{tabular}{|c|c|}
\hline \multicolumn{2}{|c|}{2011} \\
\hline Medida & Ato normativo \\
\hline Instituição do REINTEGRA & $\begin{array}{l}\text { Medida Provisória no 540/2011, posteriormente } \\
\text { convertida na Lei n. } 12.546 / 2011 \text {. }\end{array}$ \\
\hline Criação do Fundo de Financiamento à Exportação & $\begin{array}{l}\text { Medida Provisória n }{ }^{\circ} \text { 541/2011, posteriormente } \\
\text { convertida na Lei n. 12.545/2011. }\end{array}$ \\
\hline $\begin{array}{l}\text { Criação de } 120 \text { cargos de provimento efetivo da car- } \\
\text { reira de analista de Comércio Exterior para fortaleci- } \\
\text { mento da estrutura de defesa comercial }\end{array}$ & $\begin{array}{l}\text { Medida Provisória n 541/2011, posteriormente } \\
\text { convertida na Lei n. 12.545/2011. }\end{array}$ \\
\hline $\begin{array}{l}\text { Aumento da exigência de certificação compulsória e } \\
\text { fortalecimento do controle aduaneiro }\end{array}$ & $\begin{array}{l}\text { Medida Provisória n }{ }^{\circ} 541 / 2011 \text {, posteriormente } \\
\text { convertida na Lei n. } 12.545 / 2011 \text {. }\end{array}$ \\
\hline $\begin{array}{l}\text { Suspensão ex-tarifário máquinas e equipamentos } \\
\text { usados }\end{array}$ & Resolução Camex n. 55/2011. \\
\hline Combate à falsa declaração de origem & Portarias Secex n. 25 e 33 de 2011. \\
\hline Fortalecimento de combate a importações ilegais & Acordo de Cooperação MJ/MDIC, DOU 15/09/2011 \\
\hline \multicolumn{2}{|c|}{2012} \\
\hline Medida & Ato normativo \\
\hline $\begin{array}{l}\text { Ampliação dos recursos para o Programa de Finan- } \\
\text { ciamento à Exportação - PROEX }\end{array}$ & PLN 4/2012 \\
\hline Aperfeiçoamento de operações do PROEX & $\begin{array}{l}\text { Resolução CAMEX nº 21, de 04/04/2012; } \\
\text { Decreto 7.710, de 03/04/2012 } \\
\text { Resolução CMN 4.063, de 12/04/2012 }\end{array}$ \\
\hline $\begin{array}{l}\text { Adiantamento de Contrato de Câmbio (ACC) indi- } \\
\text { reto para as exportações via tradings }\end{array}$ & $\begin{array}{l}\text { MP 564, de 03/04/2012 } \\
\text { Circular BCB nº 3.592, de 02/05/2012 } \\
\text { Resolução CMN 4074, de 26/04/2012 }\end{array}$ \\
\hline Novas regras para seguro de crédito à exportação & Resolução CAMEX nº 20, de 04/04/2012 \\
\hline
\end{tabular}

13 BRASIL. Ministério do Desenvolvimento, Indústria e Comércio Exterior. Plano Brasil Maior. Disponível em: <http://www. brasilmaior.mdic.gov.br/conteudo/128>. Acesso em: 05 dez. 2013. 


\begin{tabular}{|l|l|}
\hline $\begin{array}{l}\text { Novas regras para enquadramento como Empresa } \\
\text { Preponderantemente Exportadora }\end{array}$ & MP 563, de 03/04/2012 \\
\hline $\begin{array}{l}\text { Exclusão dos sistemas Integrados da concessão de } \\
\text { ex-tarifários }\end{array}$ & Resolução CAMEX 55/2011 \\
\hline Maior controle sobre mercadorias importadas & Convênio INMETRO e RFB \\
\hline Ações antifraude da Receita Federal & $\mathrm{n} / \mathrm{a}$ \\
\hline
\end{tabular}

Essas medidas objetivam alcançar as metas traçadas pelo Plano para o comércio exterior, a saber: diversificar as exportações brasileiras e ampliar a participação do País no comércio internacional de $1,36 \%$ (2010) para 1,60\% em 2014. ${ }^{14}$

Em 2010, esse percentual de 1,36\% de participação no comércio internacional foi equivalente a 202 bilhões de dólares, sendo que, em valores da época, alcançar 1,6\% de fatia de mercado significaria um salto de aproximadamente 46 bilhões de dólares. ${ }^{15}$ Ao observar os dados consolidados de valores do final de 2012, verifica-se que o Brasil de fato ampliou em aproximadamente 40 bilhões de dólares suas exportações, mas sua fatia de mercado permaneceu inalterada em 1,3\% das exportações mundiais. ${ }^{16}$

Não houve, portanto, avanço quanto ao alcance da meta governamental. Isso porque não basta aumentar o volume de exportações como ocorreu no período 20102012. É preciso que esse aumento seja superior aos dos demais países exportadores.

Ao se observar o quadro de medidas adotadas para o comércio exterior pelo Plano Brasil Maior, percebe-se que todas estão ligadas eminentemente a três linhas de ação: ampliação de acesso ao crédito, regime tributário e aprimoramentos aduaneiros. Essa impressão é corroborada também pelo documento elaborado para apresentar o balanço de dois anos do Plano Brasil Maior. Ao tratar das medidas adotadas, o balanço executivo indica textualmente: ${ }^{17}$

14 BRASIL. Ministério do Desenvolvimento, Indústria e Comércio Exterior. Plano Brasil Maior. Disponível em: <http:// www.brasilmaior.mdic.gov.br/conteudo/128>. Acesso em: 05 dez. 2013.

15 BRASIL. Ministério do Desenvolvimento, Indústria e Comércio Exterior. Balança comercial brasileira: dados consolidados 2011. Disponível em <http://www.desenvolvimento.gov.br/arquivos/ dwnl_1365787066.pdf>. Acesso em: 05 dez. 2013.

16 BRASIL. Ministério do Desenvolvimento, Indústria e Comércio Exterior. Balança comercial brasileira: dados consolidados 2013, janeiro-junho. Disponível em < http://www.desenvolvimento. gov.br/arquivos/dwnl_1380110216.pdf>. Acesso em: 05 dez. 2013.

17 BRASIL. Ministério do Desenvolvimento, Indústria e Comércio Exterior. Plano Brasil Maior: balanço executivo, 2 anos.
As medidas de comércio exterior instituídas no âmbito do PBM incluem a concessão de isenções tributárias e crédito para estimular as exportações brasileiras, além de ações de defesa voltadas contra práticas desleais e ilegais de importações, de modo a coibir irregularidades que prejudicam os resultados comerciais do país. Entre as iniciativas de destaque, incluem-se o Reintegra, o regime de Ex-tarifários, os esforços antidumping e o aperfeiçoamento da estrutura tarifária, com a criação de mecanismo no Mercosul que permite o aumento do Imposto de Importação.

As linhas de ação adotadas até aqui pelo Plano, de fato, estão em consonância com dois objetivos da dimensão sistêmica: (i) melhoria nos instrumentos financeiros e tributários de estímulo às exportações; e (ii) defesa comercial, consolidação e harmonização de regras tarifárias.

No entanto, nenhuma das medidas adotadas pelo Plano parece atender a outro dos objetivos traçados, que é a facilitação do comércio exterior. Há, pois, descompasso claro entre objetivos traçados e ações adotadas.

Eis, então, o vácuo que os Princípios UNIDROIT de Contratos Comerciais Internacionais (UPICC ${ }^{18}$, acrônimo em inglês para UNIDROIT Principles of International Commercial Contracts) podem preencher. Como se passa a demonstrar, os Princípios são instrumento jurídico extremamente eficaz para a facilitação do comércio internacional. Por consequência, esse objetivo governamental poderia ser alcançado com sua utilização.

Disponível em: < http://www.brasilmaior.mdic.gov.br/images/data /201310/64b086d9595887261eacc81931 b9e6b4.pdf>. Acesso em: 05 dez. 2013. p. 32.

18 Opta-se aqui pela utilização da sigla em inglês, em razão de ser a expressão mais utilizada no meio acadêmico para se referir a esse instrumento. 


\section{UNIDROIT e seus Princípios de Contratos Comerciais Internacionais}

Para examinar os Princípios de Contratos Comerciais Internacionais, parece adequado apresentar, ainda que de forma sucinta, a organização que o elaborou, o UNIDROIT. Esse é um passo importante para demonstrar a relevância dos UPICC no âmbito do comércio internacional.

\subsection{Sucinto histórico do UNIDROIT}

O Instituto Internacional para Unificação do Direito Privado - UNIDROIT foi criado em 1926 como órgão auxiliar da Liga das Nações Unidas. À época, o governo italiano foi o proponente de sua criação e dispôs a custear sua manutenção. ${ }^{19}$ A proposta foi aceita pela Liga, e o UNIDROIT foi criado oficialmente em 30 de maio de 1928, tendo sua sede em Roma.

Como se sabe, a Liga das Nações teve vida curta com a eclosão da Segunda Guerra Mundial, mas o UNIDROIT conseguiu se restabelecer em 1940 como uma organização internacional multilateral. ${ }^{20}$

Atualmente, o UNIDROIT conta com sessenta e três países-membros, dentre eles o Brasil ${ }^{21}$, que contribuem financeiramente para o custeio das atividades do Instituto — à Itália compete o custeio relativo à manutenção da sede física. No orçamento de 2013, o Brasil destinou ao Instituto a quantia de R\$ $24.978,00 .^{22}$

Como o próprio nome sugere, o UNIDROIT foi fundado com o objetivo de buscar a unificação do direito privado no mundo. O artigo 1 de seu Estatuto de fundação não deixa dúvidas acerca desse objetivo ${ }^{23}$ :

19 PETERS, Lena. Unidroit. In: ENCICLOPÉDIA Max Planck de Direito Internacional Público. MPEPIL, 2007. p. 2.

20 WHITED, Christine M. The UNIDROIT Principles of international commercial contracts: an overview of their utility and the role they have played in reforming domestic contract law around the world. ILS A Journal of International and Comparative Law, Chicago, p. 168 , outono 2011.

21 A adesão do Brasil se deu em 1993, por meio do Decreto n. 884, de 02 de agosto de 1993.

22 BRASIL. Ministério do Planejamento. Orçamento federal. Disponível em: <http://www.orcamentofederal.gov.br/ orcamentos-anuais/orcamento-2013-1/portaria $\% 20$ SOF/Portaria_ SOF_07_de_280113.pdf>. Acesso em: 09 dez. 2013.

23 INTERNATIONAL INSTITUTE FOR THE UNIFICATION OF PRIVATE LAW - UNIDROIT. International Institute for the Unification of Private Law - Statute, p. 2. A
Artigo 1

Os propósitos do Instituto Internacional para Unificação do Direito Privado são examinar formas de harmonizar e coordenar o direito privado dos Estados e dos grupos de Estado, e preparar para que gradualmente leis uniformes de direito privado sejam adotadas por vários Estados. Para alcançar esse fim, o Instituto deve:

(a) preparar minutas de leis e convenções com o objetivo de estabelecer leis internas uniformes;

(b) preparar minutas de acordos com o objetivo de facilitar as relações internacionais no campo do direito privado;

(c) realizar estudos de direito comparado privado;

(d) interessar-se em projetos já estabelecidos nessas áreas por outras instituições com as quais deve estabelecer relações se necessário;

(e) organizar conferências e publicar trabalhos que o Instituto considere importantes.

Internamente, o UNIDROIT está estruturado em três grandes órgãos: (i) o Secretariado, a quem compete as atividades cotidianas; (ii) o Conselho de Governo (Governing Council), responsável pela elaboração das linhas de atuação e pela supervisão das atividades; e (iii) a Assembleia Geral, instância decisória máxima da entidade. $^{24}$

A adoção de leis uniformes por várias nações nunca foi alcançada completamente, mas o objetivo traçado pelo Estatuto do UNIDROIT serviu de norte para o trabalho de seus membros, o que resultou hoje em

transcrição acima é tradução livre. No original: Article 1 The purposes of the International Institute for the Unification of Private Law are to examine ways of harmonising and coordinating the private law of States and of groups of States, and to prepare gradually for the adoption by the various States of uniform rules of private law. To this end the Institute shall: (a) prepare drafts of laws and conventions with the object of establishing uniform internal law; (b) prepare drafts of agreements with a view to facilitating international relations in the field of private law; (c) undertake studies in comparative private law; (d) take an interest in projects already undertaken in any of these fields by other institutions with which it may maintain relations as necessary; (e) organise conferences and publish works which the Institute considers worthy of wide circulation. Disponível em: <http:// www.unidroit.org/english/presentatioguiln/statute.pdf>. Acesso em: 09 dez. 2013.

24 PETERS, Lena. Unidroit. In: ENCICLOPÉDIA Max Planck de Direito Internacional Público. MPEPIL, 2007. p. 3. 
um elevado grau de soluções harmonizadas no plano internacional. ${ }^{25}$

Os estudos produzidos pelo Instituto têm levado à produção de importantes instrumentos legais, tais como leis-modelo, guias legislativos, princípios e convenções. ${ }^{26}$ Os trabalhos são desenvolvidos em inglês e francês, mas as línguas oficiais incluem ainda o alemão, o italiano e o espanhol. Os instrumentos elaborados pelos grupos de trabalho e aprovados pela Assembleia Geral são posteriormente traduzidos em diversas outras línguas, como russo, chinês, português e árabe.

Por fim, o UNIDROIT disponibiliza ainda o UNILEX, uma base de dados para pesquisa sobre casos julgados que envolvam direito internacional privado, mais especificamente para a CISG — a Convenção das Nações Unidas de 1980 sobre Compra e Venda Internacional de Mercadorias - e para os Princípios UNIDROIT. ${ }^{27}$

\subsection{Princípios UNIDROIT de Contratos Comerciais Internacionais - UPICC}

A elaboração dos Princípios UNIDROIT de Contratos Comerciais Internacionais teve seu marco inicial em 1971, quando o Conselho de Governo incluiu no programa de trabalho do Instituto o desenvolvimento de estudos para unificação da parte geral dos contratos, com vistas a posterior codificação do direito contratual de forma mais ampla. ${ }^{28}$

25 WHITED, Christine M. The UNIDROIT Principles of international commercial contracts: an overview of their utility and the role they have played in reforming domestic contract law around the world. ILS A Journal of International and Comparative Law, Chicago, p. 171, outono 2011.

26 Como exemplo de trabalhos desenvolvidos no passado pelo Unidroit, podem-se citar: Convenção Cidade do Cabo sobre garantias internacionais sobre equipamentos móveis (2001); Princípios de Processo Civil Transnacional (2004); Guia para acordos internacionais de master franquia (2007); Lei-modelo de leasing (2008). Além disso, alguns dos temas estudados atualmente pelo Unidroit são: instrumentos de financiamento em rede; princípios e regras para fortalecer o mercado de valores mobiliários em mercados emergentes; responsabilidade civil de dispositivos de navegação por posicionamento global via satélite (GPS); relação entre direito privado e desenvolvimento econômico e social. Tudo conforme: INTERNATIONAL INSTITUTE FOR THE UNIFICATION OF PRIVATE LAW - UNIDROIT. Work in progress/studies: past studies. Disponível em: <http://www.unidroit. org/work-in-progress-studies/studies>. Acesso em: 30 jan. 2013.

27 PETERS, Lena. Unidroit. In: ENCICLOPÉDIA Max Planck de Direito Internacional Público. MPEPIL, 2007. p. 3.

28 BONELL, Michael Joachim. An international restatement of
Os estudos, discussões, encontros e elaboração de minutas perduraram de 1971 a 1994, quando finalmente a primeira versão foi lançada, com sete capítulos. ${ }^{29} \mathrm{Com}$ a evolução dos trabalhos, a segunda edição, ampliada, foi lançada em 2004 e a terceira (e atual) em 2010.

A edição atual contém 11 capítulos e 211 artigos, assim divididos: preâmbulo; disposições gerais; formação do contrato e poder de representação; validade; interpretação; conteúdo, direitos de terceiros e condições; adimplemento; inadimplemento; compensação; cessão de crédito, assunção de dívida e cessão de contrato; prazos de prescrição; pluralidade de devedores e de credores. ${ }^{30},{ }^{31}$

Como se vê, os UPICC contêm regulação sobre diversos aspectos do direito contratual e cada edição recebe novos acréscimos. Trata-se, pois, de um trabalho em contínuo processo de aperfeiçoamento. ${ }^{32}$

Há duas características que se destacam nos Princípios.

A primeira é que o trabalho dos juristas envolvidos na empreitada levou em consideração os diferentes sistemas legais, de modo que as regras contidas nos UPICC pudessem encaixar-se e ser úteis em diversos países de diferentes tradições legais. ${ }^{33}$ Quando a regra tendia a ser mais compatível com um sistema do que com o outro, o que orientou os redatores dos Princípios foi a busca da solução que contivesse o

contract law: the INTERNATIONAL INSTITUTE FOR THE UNIFICATION OF PRIVATE LAW - UNIDROIT Principles of International Commercial Contracts. New York: Transnational Juris Publication, 1994. p. 13.

29 Durante esse longo período, alguns juristas brasileiros tiveram participação na empreitada, seja como redatores, observadores ou membros da Instituição, dentre os quais se destacam: Luiz Olavo Baptista, José Carlos Moreira Alves, Luiz Gastão Paes de Barros Leães e Lauro Gama Jr.

30 INTERNATIONAL INSTITUTE FOR THE UNIFICATION OF PRIVATE LAW - UNIDROIT. Unidroit Principles of International Commercial Contracts. Disponivel em: < http:/ / www.unidroit.org/english/principles/contracts/principles 2010/ integralversionprinciples2010-e.pdf> . Acesso em: 10 dez. 2013.

31 Os títulos dos capítulos apresentados nesse rol são os que constam da versão brasileira, traduzida por Lauro Gama Jr., disponível no site do Instituto: < http://www.unidroit.org/english/ principles/contracts/principles2010/translations/blackletter2010portuguese.pdf $>$. Acesso em: 12 dez. 2013.

32 ZANOBETTI, Alessandra. UNIDROIT's recent work: an appraisal. Yearbook of Private International Law, Itália, v. 13, p. 355, 2011.

33 BONELL, Michael Joachim. An international restatement of contract law: the UNIDROIT Principles of International Commercial Contracts. New York: Transnational Juris Publication, 1994. p. 28. 
maior valor persuasivo ou que estivesse mais afinada com transações comercias internacionais. ${ }^{34}$

O segundo ponto de destaque é que os Princípios não contêm meramente os enunciados normativos. Pelo contrário, cada artigo contém comentários, explicações e exemplos a respeito de sua aplicação. ${ }^{35}$ Com isso, os Princípios transcendem um simples corpo normativo para funcionar também como um guia prática do direito do contrato comercial internacional. ${ }^{36}$

Quanto à sua natureza jurídica, os UPICC são considerados soft-law ${ }^{37}$, ou seja, sua aplicação não é cogente, tampouco precisa ser adotado por nações para ser aplicado. Nas palavras de Lauro Gama Jr. ${ }^{38}$, dentre várias conceituações doutrinárias possíveis, entendese por soft-law: "instrumentos preparados por entes não estatais, com a pretensão de estabelecer princípios orientadores do comportamento dos Estados e de outros entes, e tendendo ao estabelecimento de novas normas jurídicas."

Trata-se, portanto, de ferramenta legal elaborada por especialistas para regular contratos comercias internacionais em diferentes sistemas legais, e que vem acompanhada de um manual a respeito de sua aplicação. Sua utilização é gratuita e pode orientar todos aqueles que lidam com comércio internacional — notadamente, empresários, advogados, juízes e árbitros.

34 BONELL, Michael Joachim. An international restatement of contract law: the UNIDROIT Principles of International Commercial Contracts. New York: Transnational Juris Publication, 1994. p. 42.

35 WHITED, Christine M. The UNIDROIT Principles of international commercial contracts: an overview of their utility and the role they have played in reforming domestic contract law around the world. ILSA Journal of International and Comparative Law, Chicago, p. 169 , outono 2011.

36 O texto completo dos UPICC, com regras e comentários, estão disponíveis em inglês e francês (línguas oficiais de trabalho da Instituição) no site oficial: http://www.unidroit.org/ . Há traduções disponíveis das regras (sem os comentários) em outros dez idiomas, como chinês, húngaro, japonês e português: $<$ http://www.unidroit. org/overview-principles-2010-other-languages $>$. Acesso em: 30 jan. 2014.

37 WHITED, Christine M. The UNIDROIT Principles of international commercial contracts: an overview of their utility and the role they have played in reforming domestic contract law around the world. ILS A Journal of International and Comparative Law, Chicago, p. 176, outono, 2011. No mesmo sentido, na doutrina brasileira: GAMA JR., Lauro. Contratos internacionais à luz dos Princípios do UNIDROIT 2004: soft law, arbitragem e jurisdição. Rio de Janeiro: Renovar, 2006. p. 248.

38 GAMA JR., Lauro. Contratos internacionais à luz dos Princípios do UNIDROIT 2004: soft law, arbitragem e jurisdição. Rio de Janeiro: Renovar, 2006. p. 247.
Em seu preâmbulo, os Princípios indicam suas formas de utilização ${ }^{39}$ :

\section{Preâmbulo \\ (O objetivo dos Princípios)}

Estes Princípios estabelecem regras gerais para contratos comerciais internacionais.

Devem ser aplicados caso as partes tenham acordado que o seu contrato será regulado por eles.

Podem ser aplicados caso as partes tenham acordado que o seu contrato será regulado por princípios gerais de direito, pela lex mercatoria, ou similares.

Podem ser aplicados caso as partes não tenham escolhido nenhuma lei para regular o seu contrato.

Podem ser usados para interpretar ou suplementar instrumentos internacionais de direito uniforme.

Podem ser usados para interpretar ou suplementar leis nacionais.

Podem servir de modelo para legisladores nacionais e internacionais.

Quando as partes optarem pelo uso dos Princípios como lei aplicável ao contrato, é recomendável que optem também pela arbitragem como método de resolução de disputas, especialmente para o contrato firmado no Brasil, em razão da limitação imposta pelo artigo $9^{\circ}$ da Lei de Introdução às Normas do Direito Brasileiro, que adota a regra lex loci contractus. ${ }^{40}$ Isso significa que o contrato celebrado no Brasil deve ser regido pelas normas do direito brasileiro, não se podendo utilizar os UPICC como lei aplicável ao contrato. É o que explica Ana Tereza Basilio ${ }^{41}$ : “Aplicase no direito internacional privado brasileiro a regra da lex loci contractus, que determina que nas relações jurídicas 39 INTERNATIONAL INSTITUTE FOR THE UNIFICATION OF PRIVATE LAW - UNIDROIT. Unidroit Principles of International Commercial Contracts 2010. Roma. 2011. p. 1.

40 Trata-se da antiga Lei de Introdução ao Código Civil (LICC). A redação do artigo $9^{\circ}$ é a seguinte: "Art. $9^{\circ}$ Para qualificar e reger as obrigações, aplicar-se-á a lei do país em que se constituírem. $\int 2^{\circ} \mathrm{A}$ obrigação resultante do contrato reputa-se constituída no lugar em que residir o proponente."

41 BASILIO, Ana Tereza. Aplicação e interpretação da Convenção de Viena sob a perspectiva do direito brasileiro. Revista de arbitragem e mediação, ano 10, n. 37, p. 42, abr./jun. 2013. No mesmo sentido: ARAÚJO, Nádia de. Direito internacional privado: teoria e prática brasileira. 5. ed. atual. e ampl. Rio de Janeiro: Renovar, 2011. p. 383. 
travadas entre brasileiros e estrangeiros deve-se aplicar as leis do Estado em que residir a parte proponente do negócio jurídico firmado (cf. art. $9^{\circ}$ da LICC (Lei de Introdução às Normas Do direito Brasileiro)). Essa norma, segundo a doutrina dominante, é cogente e de ordem pública; não poderia, pois, ser modificada pela vontade dos contratantes."

Feita a opção pela arbitragem, a sistemática é diversa. É que a Lei de Arbitragem Brasileira adota a ampla liberdade das partes para escolher a lei aplicável ao contrato, como se extrai do artigo $2^{\circ}$ : “Art. $2^{\circ}$ A arbitragem poderá ser de direito ou de equidade, a critério das partes. $\int 1^{\circ}$ Poderão as partes escolher, livremente, as regras de direito que serão aplicadas na arbitragem, desde que não haja violação aos bons costumes e à ordem pública. \ $2^{\circ}$ Poderão, também, as partes convencionar que a arbitragem se realize com base nos princípios gerais de direito, nos usos e costumes e nas regras internacionais de comércio." ${ }^{42}$

Daí se conclui que, se as partes optarem pelos Princípios UNIDROIT como lei aplicável ao contrato, devem necessariamente valer-se da arbitragem como método de resolução de litígios.

Alternativamente, as partes podem utilizar os UPICC como ferramenta para elaboração de algumas de suas cláusulas contratuais, cuja negociação é normalmente difícil. É o caso, por exemplo, da cláusula de hardship, que envolve situações de desequilíbrio contratual, a permitir a renegociação dos termos pactuados. Os UPICC regulam o instituto nos artigos 6.2 .1 a $6.2 .3 .{ }^{43},{ }^{44}$ :

42 A Lei n ${ }^{\circ}$ 9.307/1996 seguiu a linha do padrão consagrado mundialmente pela Lei Modelo de Arbitragem da Uncitral, cujo artigo 35 estabelece: "Article 35. 1. The arbitral tribunal shall apply the rules of law designated by the parties as applicable to the substance of the dispute. Failing such designation by the parties, the arbitral tribunal shall apply the law which it determines to be appropriate. 2. The arbitral tribunal shall decide as amiable compositeur or ex aequo et bono only if the parties have expressly authorized the arbitral tribunal to do so. 3. In all cases, the arbitral tribunal shall decide in accordance with the terms of the contract, if any, and shall take into account any usage of trade applicable to the transaction."

43 As regras já traduzidas para o português estão disponíveis no site do INTERNATIONAL INSTITUTE FOR THE UNIFICATION OF PRIVATE LAW - Unidroit. Disponível em: <http://www.unidroit.org/english/principles/contracts/ principles 2010/translations/blackletter2010-portuguese.pdf $>$. Acesso em: 12 dez. 2013.

44 Os comentários, explicações e exemplos estão disponíveis em inglês ou francês. No documento em inglês, o tema está tratado nas páginas 212 a 222 e no site do próprio Instituto. Disponível em: <http:/ / www.unidroit.org/english/principles/contracts/principles2010/ integralversionprinciples2010-e.pdf>. Acesso em: 12 dez. 2013.
SEÇÃO 2: HARDSHIP

ARTIGO 6.2.1 (Obrigatoriedade do contrato) Quando o cumprimento de um contrato torna-se mais oneroso para uma das partes, tal parte continua, ainda assim, obrigada a cumprir o contrato, ressalvadas as disposições seguintes a respeito de hardship.

ARTIGO 6.2.2 (Definição de hardship) Há hardship quando sobrevêm fatos que alteram fundamentalmente o equilíbrio do contrato, seja porque o custo do adimplemento da obrigação de uma parte tenha aumentado, seja porque o valor da contraprestação haja diminuído, e

(a) os fatos ocorrem ou se tornam conhecidos da parte em desvantagem após a formação do contrato;

(b) os fatos não poderiam ter sido razoavelmente levados em conta pela parte em desvantagem no momento da formação do contrato;

(c) os fatos estão fora da esfera de controle da parte em desvantagem; e

(d) o risco pela superveniência dos fatos não foi assumido pela parte em desvantagem.

ARTIGO 6.2.3 (Efeitos da hardship)

(1) Em caso de hardship, a parte em desvantagem tem direito de pleitear renegociações. O pleito deverá ser feito sem atrasos indevidos e deverá indicar os fundamentos nos quais se baseia.

(2) O pleito para renegociação não dá, por si só, direito à parte em desvantagem de suspender a execução.

(3) À falta de acordo das partes em tempo razoável, cada uma das partes poderá recorrer ao Tribunal.

(4) Caso o Tribunal considere a existência de hardship, poderá, se for razoável,

(a) extinguir o contrato, na data e condições a serem fixadas, ou

(b) adaptar o contrato com vistas a restabelecer-lhe o equilíbrio.

A cláusula proposta pelos Princípios UNIDROIT é de caráter neutro, ou seja, não favorece excessivamente qualquer das partes (seller-oriented ou buyer-oriented). Nesse 
sentido, ao invés de negociar pormenorizadamente as hipóteses que permitirão (ou não) a renegociação do contrato, as partes podem optar por seguir o parâmetro já delineado pelos Princípios do UNIDROIT.

A questão da negociação da cláusula hardship ganha relevância também quando analisada a Convenção de Compra e Venda Internacional de Mercadorias (CISG), cuja entrada em vigor no Brasil se deu em abril de 2014. Embora seja um marco jurídico relevante para o incremento do comércio internacional no Brasil ${ }^{45}$, a CISG não trata do tema hardship, pelo que continua a ser necessária a negociação contratual a esse respeito.

Outro exemplo de previsão dos Princípios UNIDROIT que pode facilitar a negociação contratual é a que toca à taxa de juros a ser fixada pelo não pagamento pecuniário devido por uma das partes. Em negociações internacionais, é comum haver discrepâncias grandes a respeito de que taxas devem ser fixadas. Mais uma vez, os UPICC podem funcionar de guia seguro para negociação das partes, pois o tema está tratado nos seguintes termos ${ }^{46}$ :

\section{ARTIGO 7.4.9}

(Juros pelo não-pagamento de soma em dinheiro)

(1) Se uma parte deixa de pagar uma soma em dinheiro no momento em que é devida, a parte prejudicada tem direito a juros sobre essa soma, contados a partir de quando o pagamento era devido até o momento em que o pagamento é realizado, independentemente de $\mathrm{o}$ nãopagamento ser ou não escusável.

(2) A taxa de juros deverá ser a taxa bancária média para empréstimos de curto prazo a clientes preferenciais que vigore para a moeda de pagamento no local onde o pagamento era devido, ou, à falta de taxa nesse lugar, então a mesma taxa no Estado da moeda de pagamento. $\mathrm{Na}$ ausência dessa taxa em um e outro lugar, a taxa de juros deverá ser a taxa apropriada fixada pela lei do Estado da moeda de pagamento.

ARTIGO 7.4.10

45 RIBEIRO, Marcia Carla Pereira; BARROS, Guilherme Freire de Melo. A adesão do Brasil à CISG: eficácia, uniformização e facilitação do comércio. Pontes, v. 10, n. 3, p. 19, maio 2014.

46 As regras já traduzidas para o português estão disponíveis no site do Unidroit. Disponível em: <http://www.unidroit. org/english/principles/contracts/principles2010/translations/ blackletter2010-portuguese.pdf>. Acesso em: 12 dez. 2013.
(Juros sobre a indenização)

Salvo acordo em contrário, os juros sobre a indenização pelo inadimplemento de obrigações não-pecuniárias contam-se a partir do momento do inadimplemento.

Quando as partes são de países diferentes, sua assimetria informacional é muito grande, ou seja, há pouca informação sobre quais regras prevalecem no outro país. Os UPICC funcionam para as partes como guia seguro a respeito das práticas mais comuns e usuais do comércio internacional. Nesse contexto, a sugestão de inserção de regras dos UPICC tende a encontrar menor resistência da parte contrária.

Essa mesma lógica serve para outros temas espinhosos da negociação contratual, como perdas e danos ou a cessão do contrato.

Em suma, o que se conclui é que os Princípios UNIDROIT são ferramenta legal útil à disposição das partes para facilitação de negociação de contratos internacionais.

\section{Aplicação dos UPICC para facilitação do comércio internacional e a promoção do desenvolvimento}

Como explicitado anteriormente, um dos objetivos do Plano Brasil Maior é a facilitação do comércio internacional. Não foram adotadas, porém, quaisquer medidas concretas para alcançar esse objetivo.

Um dos obstáculos a serem superados para a realização do comércio internacional é a negociação entre as partes. Inegavelmente, as dificuldades da negociação de um contrato internacional são maiores do que as de um contrato nacional, em razão de diversos fatores como barreiras de idioma, cultura, obtenção de informações sobre a legislação do outro país, custos com advogados etc.

Tais dificuldades elevam os custos de transação do negócio e podem até mesmo inviabilizá-lo. ${ }^{47}$ Como explicam Ribeiro e Galeski Jr. ${ }^{48}$ :

47 Ronaldo Coase foi um dos pioneiros na demonstração de que todas as transações comerciais contêm custos de transação, que podem ser tão elevados a ponto de desestimular as partes a celebrar o negócio. A esse respeito: COASE, Ronald. O problema do custo social. The Latin American and Caribbean Journal of Legal Studies, v. 3, n. 1, p. 12, 2008.

48 RIBEIRO, Marcia Carla Pereira; GALESKI JÚNIOR, Irineu. Teoria geral dos contratos: contratos empresariais e análise econômica. Rio de Janeiro: Elsevier, 2009. p. 108-109. 
Os custos de acordo dizem respeito à negociação e formalização de instrumentos contratuais, como, por exemplo, a contratação de advogados ou mesmo a obtenção de informações sobre os produtos que se pretendem adquirir. Esses custos são tão altos quanto mais difíceis de se obter informações sobre os valores de intimidação e as soluções de conflitos são privadas. Por outro lado, são baixos os custos, tornando mais fáceis as negociações, quando os valores de intimidação e a solução cooperativa são públicos. [...]

A redação de um contrato também se configura como um custo de acordo, sobretudo quando se demanda por profissionais habilitados. [...]

Sendo assim, a questão dos custos de transação importa para o Direito, uma vez que, havendo presença exacerbada, seja de custos de busca, acordo ou execução, há necessidade de intervenção jurídica, como um arranjo institucional, a fim de tornar mais eficientes certas relações econômicas.

Na classificação proposta por Williamson, os custos de transação podem ser divididos em custos ex ante e ex post, ou seja, custos para se chegar ao acordo que incluem minutar, negociar e proteger - e custos posteriores ao acordo - que tocam à readaptação do contrato, à prestação de garantias e aos custos de eventuais litígios. ${ }^{49}$

Ambos os custos anteriores e posteriores são interligados ${ }^{50}$. É dizer, maiores esforços nos custos anteriores podem levar a menores custos posteriores. Se as partes passam longos dias negociando um acordo mais completo, provavelmente problemas posteriores tendem a ser evitados. Em contrapartida, se as partes fazem um acordo simples, com pouca negociação sobre as cláusulas que regerão o acordo, as chances de problemas posteriores são maiores. ${ }^{51}$

Nesse contexto, os Princípios UNIDROIT podem servir de ferramenta para reduzir os custos de transação ex ante, sem que se elevem tanto os custos de transação posteriores.

49 WILLIAMSON, Oliver. Economic institutions of capitalism. Nova York: The Free Press, 1998. p. 20-21.

50 WILLIAMSON, Oliver. Economic institutions of capitalism. Nova York: The Free Press, 1998. p. 21.

51 WILLIAMSON, Oliver. Economic institutions of capitalism. Nova York: The Free Press, 1998. p. 22.
Isso porque os UPICC estão inseridos no contexto do que vem sendo chamado de nova lex mercatoria. A globalização e, mais especificamente, a abertura das nações ao comércio internacional (globalização econômica) tem representado um novo desafio ao Estado na regulação das relações jurídicas. A complexidade dos negócios jurídicos e a internacionalização das relações comerciais têm atraído a participação de outros atores não estatais, como as organizações internacionais, as empresas transnacionais e os indivíduos. ${ }^{52}$ Como bem sintetiza Tomazette ${ }^{53}$ : "Com a globalização econômica, o Estado já não tem mais a capacidade de lidar sozinho com toda a produção normativa. Muitas relações jurídicas já não são travadas dentro de limites territoriais que sempre pautaram a produção normativa do Estado. Há a necessidade de uma internacionalização do direito que poderá se operar de diversas formas. Diante dessa situação, impõe-se o surgimento de novos atores que assumirão o papel de protagonistas inclusive na produção normativa."

O UNIDROIT é, portanto, uma dentre várias outras organizações internacionais que tem assumido protagonismo na produção normativa do comércio internacional. Nesse mesmo contexto, podem-se citar a título meramente exemplificativo a Uncitral $^{54}$ responsável, dentre outros, pela elaboração da Cisg —, a Câmara de Comércio Internacional (CCI $)^{55}$ notoriamente conhecida pelos Incoterms e por sua câmara de arbitragem - e o $\operatorname{ICSID~}^{56}$ - que resolve litígios relacionados a investimentos estrangeiros.

Os UPICC visam a servir de instrumentos de harmonização de sistemas legai ${ }^{57}$, através da construção de pontos em comum e aproximações.

52 XAVIER JUNIOR, Ely Caetano; BRANDÃO, Clarissa. Desafios globais contemporâneos: cenário de convergências no direito internacional. Revista Direito GV, São Paulo, v. 10, p. 427, jul./dez. 2009.

53 TOMAZETTE, Marlon. Internacionalização do direito além do Estado: a nova lex mercatoria e sua aplicação. Revista de Direito Internacional, v. 9, n. 4, p. 94, 2012.

54 UNCITRAL. Disponível em: <http://www.uncitral.org/ uncitral/en/index.html>. Acesso em: 12 dez. 2013.

55 INTERNATIONAL CHAMBER OF COMMERCE. Disponível em: < http://www.iccwbo.org/about-icc/>. Acesso em: 12 dez. 2013

56 INTERNATIONAL CENTER FOR THE SETTLEMENT OF INVESTMENT DISPUTES. A Instituição, criada em 1965, compõe a estrutura do Grupo Banco Mundial. Disponível em: <https://icsid. worldbank.org/ICSID/Index.jsp>. Acesso em: 12 dez. 2013.

57 TOMAZETTE, Marlon. Internacionalização do direito além do Estado: a nova lex mercatoria e sua aplicação. Revista de Direito 
Sua aplicação no contexto do Plano Brasil Maior deve ocorrer através da sua divulgação e do incentivo à sua utilização voluntária pelas partes. Não há necessidade de adoção de medidas legais ou mudanças institucionais para adoção dos UPICC. Basta que as autoridades invistam na sua promoção.

Nesse sentido, reforça-se que a proposta é a de inserção dos UPICC no contexto do Brasil Maior de forma voluntária e dirigida às partes — isso para bem pontuar a diferença entre esta opção e outros possíveis caminhos para se ampliar o comércio internacional e o desenvolvimento de países, a saber: a formação de blocos econômicos e o transplante legal de diplomas legais de países desenvolvidos para países em desenvolvimento. Vejamos cada um separadamente.

Os Princípios do UNIDROIT não precisam ser aplicados dentro do contexto de uma integração formal de sistemas, o que está mais ligado à formação de blocos econômicos. Esse caminho já é trilhado pelo Brasil através do Mercosul. Dois objetivos claros da formação dos blocos econômicos são a ampliação do comércio internacional entre os parceiros e o aumento do poder de barganha nas negociações com outras nações e outros blocos. A respeito desse último, a atuação do Mercosul tem sido bastante tímida, tendo fechado poucos acordos comerciais significativos nos últimos anos, tais como os com Israel (2007), Egito (2010) e Índia (2009).$^{58}$ Como bem alertam Winter e Hastreiter, a integração regional demanda "enorme vontade política dos países membros, justamente porque implica em uma releitura dos conceitos de soberania dos Estados." "59 A integração econômica envolve questões macropolíticas e macroeconômicas complexas, a serem superadas através de longas reuniões diplomáticas.

Já a aplicação dos Princípios do UNIDROIT para facilitação do comércio internacional não envolve arranjos políticos específicos, senão apenas a vontade das partes. Trata-se, pois, de instrumento que se liga intimamente à microeconomia, à redução nos custos de transação da negociação do contrato pelas partes.

Internacional, v. 9, n. 4, 2012, p. 108.

58 CESAR, Susan Elizabeth Martins; SATO, Eiiti. A Rodada Doha, as mudanças no regime do comércio internacional e a política comercial brasileira. Revista Brasileira de Politica Internacional, v. 55, n. 1, p. 187, 2012.

59 WINTER, Luís Alexandre Carta; HASTREITER, Michele Alessandra. Mercosul e acordos entre blocos: perspectivas e novas cláusulas em acordos de comércio. In: WINTER, Luís Alexandre Carta et al. (Org.). Direito Internacional, Florianópolis: Funjab, p. 421. 2013.
Por outro lado, a inserção dos UPICC no contexto do Plano Brasil Maior defendida neste artigo não envolve o seu transplante para nosso ordenamento jurídico. Nas últimas duas décadas, diversas nações, muito influenciadas pelo Banco Mundial, adotaram as bases teóricas que defendiam o transplante de legislações de países desenvolvidos para países em desenvolvimento, ao argumento de que o arranjo jurídico institucional adequado seria suficiente para promover o desenvolvimento. ${ }^{60}$ Esse movimento estava intimamente ligado ao Consenso de Washington e ficou conhecido pelo signo do one size fits all. ${ }^{61}$

Inegavelmente, os Princípios do UNIDROIT podem ser utilizados no contexto de reforma legislativa, como enuncia o seu próprio preâmbulo. ${ }^{62} \mathrm{E}$ de fato isso tem ocorrido, como demonstram os exemplos das reformas legislativas na Lituânia ${ }^{63}$, na China ${ }^{64}$ e na Organização para Harmonização do Direito Comercial na África ${ }^{65}$ (Ohada, no acrônimo em francês). Há de se destacar, porém, que a utilização dos UPICC como parâmetro para reforma legislativa não é o mesmo que

60 DAVIS, Kevin; TREBILCOCK, Michael J. A relação entre direito e desenvolvimento: otimistas versus céticos. Revista Direito GV, São Paulo, v. 9, p. 224, jan./jun. 2009.

61 SCHAPIRO, Mario Gomes. Repensando a relação entre Estado, direito e desenvolvimento: os limites do paradigma Rule of law e a relevância das alternativas institucionais. Revista Direito GV, São Paulo, v. 11, p. 223, jan./jun. 2010.

62 INTERNATIONAL INSTITUTE FOR THE UNIFICATION OF PRIVATE LAW - UNIDROIT. Unidroit Principles of International Commercial Contracts 2010. Roma. 2011. p. 1: "Podem servir de modelo para legisladores nacionais e internacionais."

63 Após o desmembramento da União Soviética, a Lituânia promulgou seu novo Código Civil em 2000, tendo os Princípios Unidroit como guia. Fonte: WHITED, Christine M. The UNIDROIT Principles of international commercial contracts: an overview of their utility and the role they have played in reforming domestic contract law around the world. ILS A Journal of International and Comparative Law, Chicago, p. 183, outono 2011.

64 O direito contratual chinês foi reformado em 1999, e os redatores da nova legislação utilizaram as regras dos UPICC sobre formação do contrato como base. Fonte: WHITED, Christine M. The UNIDROIT Principles of international commercial contracts: an overview of their utility and the role they have played in reforming domestic contract law around the world. ILSA Journal of International and Comparative Law, Chicago, p. 188, outono 2011.

65 Nesse caso, a Ohada solicitou formalmente o auxílio do Unidroit para elaboração de uma legislação comercial uniforme, que teve naturalmente como ponto de partida os UPICC. Fonte: WHITED, Christine M. The UNIDROIT Principles of international commercial contracts: an overview of their utility and the role they have played in reforming domestic contract law around the world. ILSA Journal of International and Comparative Law, Chicago, p. 191, outono 2011. 
realizar o simples transplante de diplomas jurídicos de países desenvolvidos, já que os Princípios UNIDROIT foram elaborados com base em diferentes sistemas legais e congregam regras consagradas no comércio internacional, pelo que possuem caráter mais universal do que uma lei nacional transplantada.

Ainda assim, o modelo de transplante legal utilizado tão largamente nos últimos anos não é garantia de solução para sustentar desenvolvimento vigoroso para um país. Como destaca Schapiro ${ }^{66}$, com apoio em Carles Sabel, "se é inegável que o arranjo institucional é uma variável dos processos de desenvolvimento, é absolutamente controversa a noção de que há um único padrão de organização econômica adequada transplantável para os mais distintos países. A rigor, o sucesso ou insucesso dos países está associado à sua capacidade de desenhar um marco institucional articulado e adequado a cada contexto particular."

Em suma, a aplicação dos UPICC no Plano Brasil Maior não perpassa a integração comercial por blocos, nem tampouco a modificação no direito positivo brasileiro. Os Princípios UNIDROIT podem seguir por outra via para facilitar o comércio internacional, que é a sua aplicação pelos particulares. Sua utilização permite que as partes cheguem mais rapidamente a acordos sobre as regras contratuais que vão reger seu negócio jurídico. Nesse sentido, não são Estadosnações que dialogam em busca de um marco jurídico comum, mas particulares que utilizam plenamente sua autonomia da vontade para estabelecer as regras jurídicas de sua relação.

Como destaca Tomazette ${ }^{67}$, o bom funcionamento dos mercados demanda a existência de um panorama normativo que lhe seja favorável e adequado - em suas palavras: "Com efeito, nos mercados globais, há certas exigências para o seu correto funcionamento, que alguns autores sintetizam em três ideias: a necessidade da unidade das normas aplicáveis aos negócios internacionais; a facilidade de utilização e compreensão da norma pelos agentes que atuam no mercado; e a segurança na aplicação das referidas normas".

66 SCHAPIRO, Mario Gomes. Amarrando as próprias botas do desenvolvimento: a nova economia global e a relevância de um desenho jurídico-institucional nacionalmente adequado. Revista Direito GV, São Paulo, v. 13, p. 343, jan./jun. 2011.

67 TOMAZETTE, Marlon. Internacionalização do direito além do Estado: a nova lex mercatoria e sua aplicação. Revista de Direito Internacional, v. 9, n. 4, p. 109, 2012.
Os UPICC proporcionam exatamente isso de que fala o autor - nessas três dimensões:

(i) necessidade de unidade de normas aplicáveis aos negócios internacionais: suas regras foram elaboradas precisamente para regular contratos comerciais internacionais. Os redatores eram (e são) especialistas na matéria e buscaram soluções harmônicas tanto para os sistemas de common law, quanto para o de civil law.

(ii) facilidade de utilização e compressão da norma pelos agentes que atuam no mercado: os UPICC não contêm apenas o texto normativo descritivo de direito e deveres. Cada regra contém notas explicativas e exemplos de sua aplicação. Trata-se, portanto, de instrumento jurídico de fácil compreensão, inclusive por aqueles não letrados em direito.

(iii) segurança na aplicação das referidas normas: para garantir a plena aplicabilidade dos Princípios, convêm que as partes façam menção expressa à sua aplicação ao contrato e optem pela resolução de litígios por arbitragem.

Como se vê, os UPICC possuem características adequadas para reduzir os custos de negociação de contratos internacionais. A questão é que essa ferramenta ainda é pouco conhecida no Brasil. Por isso, a divulgação e promoção dos UPICC no contexto da política governamental do Plano Brasil Maior pode impulsionar sua utilização como instrumento eficaz de facilitação do comércio exterior.

\section{Conclusão}

O desenvolvimento de uma nação está associado à melhoria da qualidade de vida de seus cidadãos. Para alcançar tal desiderato, o Brasil busca aumentar sua riqueza interna por meio de estratégias que envolvem políticas industriais, tecnológicas e de comércio exterior.

O Plano Brasil Maior apresenta como um de seus objetivos a facilitação do comércio exterior. As medidas adotadas, porém, estão ligadas apenas a questões tributárias, aduaneiras e de defesa comercial.

O Brasil, como país membro do UNIDROIT, contribui financeiramente para a manutenção da Instituição e desenvolvimento de seus trabalhos. Via de consequência, o governo brasileiro investiu (e continuará investindo) anualmente no desenvolvimento de ferramentas legais como os Princípios UNIDROIT de Contratos Comerciais Internacionais. Cumpre, 
então, dar utilidade à ferramenta que ajudou a elaborar — não só com esforços financeiros, mas intelectuais de juristas brasileiros - em benefício próprio, em prol do desenvolvimento econômico do País.

Os Princípios UNIDROIT podem fazer parte da política de comércio exterior através da divulgação e do incentivo à sua utilização pelos exportadores brasileiros.

Como a negociação de contratos internacionais é sempre mais complexa e demorada, os custos de transação se elevam, e os acordos podem não ocorrer. As partes podem seguir duas sistemáticas distintas nesse ponto: escolher os Princípios UNIDROIT como lei de regência do contrato - necessariamente com a escolha da arbitragem como método de solução de disputas - ou inserir o texto dos Princípios UNIDROIT no contrato em forma de cláusulas contratuais. A utilização dos Princípios UNIDROIT pelas partes pode contribuir para superar algumas das dificuldades da negociação, pois são instrumento desenvolvido especificamente para o comércio internacional e possuem não apenas texto normativo, mas também notas explicativas e exemplos.

Trata-se, portanto, de guia seguro e eficaz para negociação de contratos internacionais.

\section{Referências}

ARAÚJO, Nádia de. Direito internacional privado: teoria e prática brasileira. 5. ed. atual. e ampl. Rio de Janeiro: Renovar, 2011.

BANCO MUNDIAL, Brazil. Disponível em: <http://data. worldbank.org/country/brazil>. Acesso em: 05 dez 2013.

BASILIO, Ana Tereza. Aplicação e interpretação da Convenção de Viena sob a perspectiva do direito brasileiro. Revista de arbitragem e mediação, ano 10, n. 37, abr./jun. 2013.

BONELL, Michael Joachim. An international restatement of contract law: the UNIDROIT Principles of International Commercial Contracts. Nova York: Transnational Juris Publication, 1994.

BRASIL. Banco Central. Série histórica do balanço de pagamentos. Disponível em: <http://www.bcb.gov. br/?SERIEBALPAG>. Acesso em: 05 dez. 2013.

BRASIL. Ministério do Desenvolvimento, Indústria e Comércio Exterior. Balança comercial brasileira: dados consolidados 2013, janeiro-junho. Disponível em $\quad<$ http://www.desenvolvimento.gov.br/arquivos/ dwnl_1380110216.pdf>. Acesso em: 05 dez. 2013.

BRASIL. Ministério do Desenvolvimento, Indústria e Comércio Exterior. Política de Desenvolvimento Produtivo. Disponível em: <http://www.pdp.gov.br/ paginas $/$ macrometas.asp $x$ ? Language $=E \&$ Country $=\mathrm{BR}>$. Acesso em: 12 dez. 2013.

BRASIL. Ministério do Desenvolvimento, Indústria e Comércio Exterior. Plano Brasil Maior. Disponível em: $<$ http://www.brasilmaior.mdic.gov.br/conteudo/128>. Acesso em: 05 dez. 2013.

BRASIL. Ministério do Planejamento. Orçamento federal. Disponível em: <http://www.orcamentofederal.gov.br/ orcamentos-anuais/orcamento-2013-1/portaria\%20SOF/ Portaria_SOF_07_de_280113.pdf $>$. Acesso em: 09 dez. 2013.

CESAR, Susan Elizabeth Martins; SATO, Eiiti. A Rodada Doha, as mudanças no regime do comércio internacional e a política comercial brasileira. Revista Brasileira de Política Internacional, v. 55, n.1, p. 174-193, 2012.

COASE, Ronald. O problema do custo social. The Latin American and Caribbean journal of legal studies, v. 3, n. 1, p. 12, 2008.

CONTI, Mario Sérgio. Notícias do planalto: a imprensa e Fernando Collor. São Paulo: Companhia das Letras, 1999.

DAVIS, Kevin E. TREBILCOCK, Michael J. A relação entre direito e desenvolvimento: otimistas versus céticos. Revista Direito GV, São Paulo, v. 9, p. 217-268, jan./jun. 2009.

GAMA JR., Lauro. Contratos internacionais à luz dos Princípios do UNIDROIT 2004: soft law, arbitragem e jurisdição. Rio de Janeiro: Renovar, 2006.

INTERNATIONAL CENTER FOR THE SETTLEMENT OF INVESTMENT DISPUTES. Disponível em: < https:// icsid.worldbank.org/ICSID/Index.jsp.> . Acesso em: 12 dez. 2013

INTERNATIONAL CHAMBER OF COMMERCE. $<$ http://www.iccwbo.org/about-icc/>. Acesso em: $12 \mathrm{dez}$. 2013.

INTERNATIONAL INSTITUTE FOR THE UNIFICATION OF PRIVATE LAW - UNIDROIT. International Institute for the Unification of Private LawStatute. Disponível em: <http://www.unidroit.org/english/ presentation/statute.pdf.> Acesso em: 09 dez. 2013.

INTERNATIONALINSTITUTEFORTHEUNIFICATION 
OF PRIVATE LAW - UNIDROIT. UNIDROIT Principles of International Commercial Contracts. Disponível em: $<$ http://www.unidroit.org/english/principles/contracts/ principles2010/integralversionprinciples2010-e.pdf>. Acesso em: 10 dez. 2013.

INTERNATIONAL INSTITUTE FOR THE UNIFICATION OF PRIVATE LAW - UNIDROIT. UNIDROIT Principles of International Commercial Contracts: black letter rules: portuguese. Disponível em $<$ http://www.unidroit.org/english/principles/contracts/ principles2010/integralversionprinciples2010-e.pdf>. Acesso em: 12 dez. 2013

INTERNATIONALINSTITUTEFORTHEUNIFICATION OF PRIVATE LAW - UNIDROIT. UNIDROIT. Work in progress/studies: past studies. Disponível em: <http:// www.unidroit.org/work-in-progress-studies/studies $>$. Acesso em: 30 jan. 2013.

LEITÃO, Miriam. Saga brasileira: a longa luta de um povo por sua moeda. São Paulo: Record, 2011.

PETERS, Lena. UNIDROIT. In: ENCICLOPÉDIA Max Planck de Direito Internacional Público. MPEPIL, 2007.

RIBEIRO, Marcia Carla Pereira; BARROS, Guilherme Freire de Melo. A adesão do Brasil à CISG: eficácia, uniformização e facilitação do comércio. Pontes, v. 10, n. 3, p. 19, maio 2014.

RIBEIRO, Marcia Carla Pereira; GALESKI JÚNIOR, Irineu. Teoria geral dos contratos: contratos empresariais e análise econômica. Rio de Janeiro: Elsevier, 2009.

SCHAPIRO, Mario Gomes. Amarrando as próprias botas do desenvolvimento: a nova economia global e a relevância de um desenho jurídico-institucional nacionalmente adequado. Revista Direito GV, São Paulo, v. 13, p. 341352, jan./jun. 2011.
SCHAPIRO, Mario Gomes. Repensando a relação entre Estado, direito e desenvolvimento: os limites do paradigma Rule of law e a relevância das alternativas institucionais. Revista Direito GV, São Paulo, v. 11, p. 213-252, jan./jun. 2010.

TOMAZETTE, Marlon. Internacionalização do direito além do Estado: a nova lex mercatoria e sua aplicação. Revista de Direito Internacional, v. 9, n. 4, p. 93-121, 2012.

UNCITRAL. $\quad<$ http://www.uncitral.org/uncitral/en/index. html >. Acesso em:12 dez. 2013.

WHITED, Christine M. The UNIDROIT Principles of international commercial contracts: an overview of their utility and the role they have played in reforming domestic contract law around the world. ILSA Journal of International and Comparative Law, Chicago, p. 167-191, outono 2011.

WILLIAMSON, Oliver. Economic institutions of capitalism. Nova York: The Free Press, 1998.

WINTER, Luís Alexandre Carta; HASTREITER, Michele Alessandra. Mercosul e acordos entre blocos: perspectivas e novas cláusulas em acordos de comércio. In: WINTER, Luís Alexandre Carta et al. (Org.). Direito Internacional. Florianópolis: Funjab, 2013. p. 420-437.

XAVIER JUNIOR, Ely Caetano; BRANDÃO, Clarissa. Desafios globais contemporâneos: cenário de convergências no direito internacional. Revista Direito GV, São Paulo, v. 10, p. 435-442, jul./dez. 2009.

ZANOBETTI, Alessandra. UNIDROIT's recent work: an appraisal. Yearbook of private international law, Itália, v. 13, p. 345-365, 2011. 
Para publicar na Revista de Direito Internacional, acesse o endereço eletrônico www.rdi.uniceub.br ou www.brazilianjournal.org.

Observe as normas de publicação, para facilitar e agilizar o trabalho de edição. 